\title{
Rehabilitation Outcomes for Children with Cochlear Implants in Tanzania
}

\author{
Fayaz Mehboob Jaffer* \\ Master of Clinical Audiology and Hearing Therapy, 2017, School of Advanced Education Research and Accreditation, Universidad Isabel I - Spain, \\ Tanzania
}

Submission: September 04, 2017; Published: September 11, 2017

*Corresponding author: Fayaz Mehboob Jaffer, Master of Clinical Audiology and Hearing Therapy, 2017, School of Advanced Education Research and Accreditation, Universidad Isabel I - Spain, Tanzania, Tel: +255 713 234 567; Email: hearwell.tz@gmail.com

\begin{abstract}
Introduction: In Tanzania, there is little awareness of hearing loss and rehabilitative measures that can be used to effectively manage it. This study considers the outcomes of children in Tanzania who have cochlear implants and aims to measure the outcomes of the rehabilitation they currently undergo. The research aimed to establish the relationship between rehabilitation outcomes in implantees and the frequency of the rehabilitative sessions they attend. It was carried out to quantify this variable and its effect on gaining better outcomes for rehabilitation.

Participants: 15 children between ages 1 and 6 who attend speech therapy sessions at Hearwell Audiology Clinic, out of which 13 are unilaterally implanted and 2 are bilaterally. They were assigned to two groups, Group $1(n=5)$ being the group that attended therapy sessions 3 or more times a week, and Group $2(\mathrm{n}=10)$ being the children that attended once a week, on average.

Method: The children's outcomes were assessed using the Little Ears Auditory Questionnare (LEAQ) and the Meaningful Auditory Integration Scale (MAIS), both administered at one year of hearing age. These questionnaires focus on auditory development and comfort and habits of using the cochlear implants.

Results: Group 1 had mean scores of 23.6/35 for the LEAQ and 30.8 for the MAIS, while Group 2 had mean scores of 14.1/35 for the LEAQ and 26.2 for the MAIS.

Conclusion: Children who attended more sessions of speech therapy showed better scores, displaying a positive correlation between outcomes and attendance to rehabilitation sessions. These results imply that, as awareness of hearing impairment increases in Tanzania, the need for effective rehabilitation should be stressed, as it could promote better outcomes, especially in low resource settings. To date, there has been no similar research in this field as yet for this region, and this being the first of such, it is my hope that it will encourage more future researches that are further indepth and more generalized.
\end{abstract}

\section{Chapter I: Hearing Impairment}

\section{Introduction}

\section{Hearing impairment}

Disabling hearing loss affects over $5 \%$ of the world's population - about 360 million people worldwide [1]. Hearing impairment can be defined as any loss of the ability to detect sound, and has different causes, depending on the part of the auditory pathway that is being affected. The auditory system consists of three main parts; the external ear, the middle ear, and the inner ear. The external ear is formed by the pinna, the part of the ear that is externally visible, and the ear canal, which both function to funnel sound waves towards the tympanic membrane. The middle ear begins at the tympanic membrane, or eardrum, and is primarily constituted of the ossicles - three tiny bones, attached to each other, and to the eardrum on one end and the oval window on the other. As the eardrum vibrates when sound waves hit it, it sets the ossicles into motion too, which transfer this energy on to the fluid in the cochlea via the oval window.

The cochlea, the hearing portion of the inner ear, is where sensory hair cells detects the energy passed into the fluid and convert it to neural impulses. These impulses then travel through the vestibulocochlear nerve, the VIII ${ }^{\text {th }}$ Cranial nerve, and ascend the auditory pathway to the auditory cortex of the brain. When any of these portions of the auditory system are not functioning as they should be, an individual's ability to hear may be impaired. This loss of hearing can in turn have a range of effects on an individual's life; from having social consequences to having psychological and even physiological impacts on one's life. These consequences of hearing loss affect the quality of everyday life; and an estimated $10 \%$ of populations in a number 


\section{Global Journal of Otolaryngology}

of Western countries have a degree of hearing impairment that affects their daily lives [2].

Hearing impairment causes disabilities of many kinds - as a sensory impairment, it firstly presents as the loss of the ability to detect sounds, to discriminate and recognize sounds or speech, and to localize sounds [2]. Even a slight loss can hamper normal sensory abilities, people with mild to moderate hearing losses reported that they often have problems understanding speech when background noise is present [3]. Additionally, the difficulty in detecting sounds is not confined to speech sounds, but rather involves environmental sounds as well. Sounds such as those of phones and alarms may be missed, and one could also face difficulties in detecting sounds that may be signaling the presence of a danger; traffic sounds, for example.

Hearing loss therefore has a large impact on an individual's life, and with its effect on hearing and understanding speech, it largely affects one's communication with others. Hearing impaired people have to concentrate much more so that they can pick up speech, and the effort that this requires may cause fatigue. Other people also need to put extra effort into communication with hearing impaired people; they may need to stand closer, speak slower and louder, face the person directly, and speak much more clearly. Due to this, one may find that hearing loss could affect an individual's social life. A study by Weinstein and Ventry [4] was conducted to determine whether there is a relationship between hearing impairment and feelings of social isolation, and the results showed that in individuals over the age of 65 there was a strong correlation between scores of social isolation and audiological measures of hearing loss.

Hearing loss can also have an impact on the education and employment of an individual. The effect varies, majorly dependent on when the onset of hearing loss occurred, and the degree of the impairment. For adults or postlingual children, while there is a loss of functional hearing ability, other competencies may not be majorly affected. For prelingual children however, there is a great impact on the development of language, on education, and as a direct consequence, on employment. The effect of hearing impairment on education can be increasingly negative in children's lives; Blanchfield et al. [5] reported a 44\% rate of high school dropouts for deaf students, compared with a $19 \%$ dropout rate for the general population that was sampled.

In Tanzania, there are no studies into the prevalence of hearing loss for the population of the country. According to the World Health Organization's global estimates for prevalence of hearing loss [6], the prevalence of disabling hearing loss in children i.e. impairment greater than $30 \mathrm{~dB}$ in the better ear, is third greatest in the Sub Saharan Africa region, under which Tanzania falls. Another study placed Sub Saharan Africa as the region with the second highest prevalence of disabling hearing loss in children, with an estimated 4.1 million children with hearing impairment [7], meaning that their development of speech and language could be impacted, and therefore their cognitive development could also be impacted. This highlights the need for intervention and rehabilitation programs for hearing loss in children in regions where it is prevalent; Tanzania being part of one such region.

\section{Types of Hearing Loss and Causes}

There are two primary types of hearing loss, conductive hearing loss and sensorineural hearing loss. Each type of hearing loss affects a different part of the auditory system, has a different range of causes, and therefore has different management options. A third type of hearing loss is known as a mixed hearing loss, and is the combination of a conductive and sensorineural hearing loss. Conductive hearing loss occurs due to an obstruction or impedance to the transfer of energy through the external and/or middle ear. This usually results in a flat hearing loss, i.e. a similar loss across all the frequencies, of up to $60 \mathrm{~dB}$ [8]. Conductive hearing loss can be a consequence of a range of causes, most of which can be managed via medical or surgical methods, after which an individual's hearing levels would most likely be restored.

Some causes are more easily treatable than others; a loss caused by wax build up in the ear canal can be negated through the removal of the wax via irrigation or other suitable methods [9]. A common proponent of conductive hearing loss is an infection of the middle ear; an estimated five out of six children experience otitis media by the age of three [10]. The mismanagement or neglect of a majority of conditions that may cause a conductive hearing loss could result in more serious complications, such as a permanent sensorineural hearing loss.

The second type of hearing loss is known as a sensorineural hearing loss. As the name suggests, these hearing losses have a sensory or neural element, and therefore are typically due to defects in the inner ear and onwards. Sensorineural hearing loss is more common than conductive losses, and in most cases, is irreversible [11]. Sensorineural hearing losses are often typified by the deficiency or damage of hair cells in the cochlea, resulting in a decreased sensitivity to sound of the cochlea, as the absence of hair cells would mean diminished stimulation of the auditory nerve. In cases of profound losses, a cochlear dead region may be present. These can be defined as regions of the cochlea with very few or no functioning inner hair cells/ neurons [12], and therefore as a result, the range of sounds that the region was particularly sensitive to is lost.

In the cochlea, the hair cells are arranged on the basilar membrane in a pattern that allows individual auditory nerve fibers to be highly tuned to specific frequencies [13]. This is firstly due to the structural properties of the basilar membrane; it is stiffer and narrower at the base, and wider and flexible at the apex. This allows for sound to be propagated from the stiffer portion towards the more flexible one. Von Békésy [14] studied the movement of the basilar membrane and showed that due to these properties, a traveling wave is formed in the cochlea when stimulated by sound, and this wave grows and 
slows down as it propagates, until it reaches the point of its maximal displacement. This point's position on the membrane is dependent on the frequency of sound that is introduced to the cochlea; points of maximum displacement in response to high frequency sounds are towards the base of the membrane, while the points that correspond with low frequency sounds are at the apex.

This phenomenon allows for the ton topical organization of the auditory system, where specific regions are said to respond to specific frequencies, and this is an occurrence observable throughout the system: from the basilar membrane of the cochlea, to the organization in the fibers of the auditory nerve, and even to the primary auditory cortex in the brain [13]. This tonotopic organization of the basilar membrane is a phenomenon that is vital when studying how a cochlear implant functions, which will be looked at in depth in the next section. Sensorineural hearing losses have an observable effect on speech perception and the ability of an individual to pick up speech in background noise. While conductive losses simply require a greater level of sound to achieve the same scores as normal hearing people, sensorineural hearing impairment may cause distortion of sounds that are presented to the cochlea.

This effect can be seen via speech audiometry tests and in particular, when testing for the speech recognition threshold and finding the patient's word recognition score. The former is the lowest level at which one can identify a sound from a list of disyllabic words, while the word recognition score is a score of the number of correct words recognized out of a list of presented words [15]. For normal hearing individuals, a score between 85 and $100 \%$ is expected, but as hearing impairment increases, the patient's score decreases. In profound hearing losses, a loss of speech intelligibility is observable and distortion occurs at intensities higher than $80 \mathrm{~dB}$, making word and speech recognition increasingly difficult [15].

\section{Intervention for Hearing Impairment}

Intervention for individuals with hearing impairment involves multiple types and faculties for the improvement of the lives of these individuals. For patients with conductive hearing losses, surgical or medical intervention is usually required to manage the complication causing the hearing loss, after which the individual's hearing is normally restored. For patients with more permanent, sensorineural hearing loss, interventions are usually dependent on the degree of impairment suffered by the patient, and the type of residual hearing that is available. Additionally, the efficacy of intervention differs from patient to patient, what one patient could find beneficial might not work for another patient, even if their audiometric tests are of similar configuration.

This section focuses on the technology that offers intervention for the hearing impaired. The first, and most common device offered to patients is the hearing aid. A hearing aid is a device that picks up sounds from the environment, amplifies and processes these sounds, and then delivers the processed sound wave into the person's ear. The second device offered to patients is the cochlear implant. It is important to note that the cochlear implant is only offered to candidates who meet set criteria that differ from one country to another depending on the maturity of the cochlear implant program in the respective country. For example, more developed countries have been doing Cochlear Implant surgeries for a very long time and hence have lowered the criteria, from implanting only patients with profound hearing loss to now implanting individuals with partial deafness as well.

As a rule of thumb, cochlear implants are usually more beneficial in cases of profound hearing impairment, not being normally required in cases of milder losses where hearing aids provide ample benefit. Cochlear implants function by directly stimulating the auditory nerve electrically, and therefore bypass the auditory systems conductive mechanisms and the sensory hair cells as well. The third category of devices can be referred to as assistive devices, and encompasses all other devices that aim to help the hearing impaired in their daily lives. This category includes the use of loop systems for hearing aids, flashing or vibrating alarms and devices, amplified or text telephones, teletypewriters, and the like [16].

\section{Hearing Aids}

Hearing aids are the most commonly used device in managing hearing impairment, offering amplification that is adjustable depending on an individual's degree of hearing loss. Devices for amplification for those with hearing loss have been available for a long time; prior to the development of electrical technology, funnel shaped devices called ear trumpets were used to provide acoustic amplification. After the development of the telephone, and more specifically the receiver in 1876, this invention opened up a world of possibilities for the development of amplification [17]. In the early 20th century, the vacuum tube came along, offering $70 \mathrm{~dB}$ of gain and an even frequency response. The first models were not very practical, weighing about $100 \mathrm{~kg}$, but later developments produced one that was much smaller and weighed just $4 \mathrm{~kg}$ [17]. The first wearable hearing aid was developed in 1938, and these required a battery pack that was housed separately from the amplifier.

A decade later, body worn aids as we know them today were developed, and using subminiature vacuum tubes, all the components of the hearing aid could be housed in one unit that was then connected to an earpiece using a wire. The solution to this was the invention of the transistor, which found it being used in hearing aids more than vacuum tubes. Following this development, the first hearing aids worn completely at the ear were developed, by integrating the components of hearing aids into spectacle frames. These gave way to the development of the behind the ear hearing aids that we are familiar with today. These early models utilized analog signal processing, however as the turn of the century approached, digital signal processing was being applied to most hearing aids, either in conjunction with 


\section{Global Journal of Otolaryngology}

analog systems, or in fully digital models that allowed a greater ability to fine tune hearing aids and the amplification offered to suit an individual's hearing loss [17].

Today, hearing aids are capable of a large number of functions, and come in a range of styles, all geared to suit the consumer's needs. The function of a hearing aid is to amplify sounds to a degree and manner that enables a person with impairment to use their residual hearing effectively [18]. Digital hearing aids function by converting a sound wave into analog signals and then into binary digits, which represent the characteristics of the wave and allow more intricate processing to be utilized. The processed signal is then converted back into an analog signal, which is transmitted to the receiver and then passed on into our ears [19]. Hearing aids therefore are a marveling piece of technology, and the incorporation of their components enables individuals with hearing impairment to be offered intervention that may prove very effective in correcting the hearing loss.

Hearing aids come in a number of styles and types; firstly, there are the common behind the ear hearing aids, referred commonly to as BTEs. These are the standard hearing aids that are offered to patients, and the components are housed in a case that is worn behind the pinna, hence the name. A thin acoustic tube or wire connects the case to the ear canal, via the use of a dome or custom made ear mould. BTE hearing aids are widely used due to their availability, the range of functions they possess, and their wide fitting ranges. They also come in a variety of sizes and colors; generally, the greater the hearing loss, the greater the size of the hearing aid. These are the most appropriate hearing aids for more severe hearing losses, or for consumers with complex needs. They are equipped with a number of functionalities to achieve the ability to benefit the impaired hearing; functions such as directional microphones, noise cancellation, feedback managers, loop system functionality, and direct auditory input, to name a few. Digital hearing aids are also equipped with multiple channels, these allow factors like amplification (gain) and compression to be manipulated independently for frequencies that are separated into these channels, allowing for a hearing aid's response to be customized and fit to accurately suit an individual's audiogram and preferences.

Recently, a new type of BTE has become more prevalent in the hearing care sector today, the Receiver in the Ear/Receiver in the Canal aid, also known as the RITE or RIC. This subtype of behind the ear hearing aids have, as of late, become a category of their own due to their popularity amongst users and providers. The main key difference from traditional BTEs, as the name suggests, is that the receiver is not housed within the hearing aid casing, but rather sits in the canal of the ear and is connected to the casing of the aid via a thin electrical cable. These hearing aids in 2012 made up around $45 \%$ of hearing aids sold in the US [20]. RITE aids became popular due to a number of reasons; the ability to interchange receivers when higher power is required is convenient for audiologists when fitting these aids. They also provide more gain with less risk of feedback [21], as the receiver is located in the ear canal while the microphone is housed in the case that sits behind the pinna. They could offer a smoother frequency response, once again due to the positioning of the receiver, and do not face problems that traditional BTEs face with moisture collecting in the acoustic tubing. The disadvantage of these aids is the conditions in the canal that the receiver would be subject to; the warm, moist and oily conditions are generally not friendly to electrical devices.

The second types of hearing aids are in the ear hearing aids, also referred to as ITEs. This type also includes in the canal, or ITC, hearing aids and completely in canal, or CIC hearing aids. These are custom made hearing aids, and all of the components of the aid are housed in a shell that is made from an impression of the patient's ear, similar to how ear moulds are made. These hearing aids are seen as being more convenient for wearers; as everything is housed in a single unit, they are seen as easier to handle than aids with ear molds. They are also more discreet than BTE aids, studies into hearing aid non-use show that a number of individuals do not prefer hearing aids due to cosmetic reasons [22]. ITE hearing aids fit in the ear, and are less visible than some of the more apparent BTE versions. Users of ITEs also report more natural sound, as the microphone on the ITE sits in the ear canal rather than behind the ear, and therefore also allows for the pinna notch effects to occur to some degree.

ITEs are slightly different from ITCs as they fill the concha bowl too, while ITCs simply sit inside the canal, with little that is externally visible. The size and placement of these hearing aids, however, do slightly limit their functionality. Modern ITEs can fit for almost any degree of hearing loss, but ITCs are usually only appropriate in cases that suffer from degrees of hearing loss up to moderate-to-severe impairment. CICs are even more limited, being best for individuals with mild to moderate hearing impairments. This is due to their size, they have a limited ability to provide high levels of gain, and there is a great possibility of feedback. These hearing aids are also a little less durable than BTEs as they are subject to the warm and moist conditions of the ear canal, with the presence of wax also being a reason for their vulnerability [19].

A third and less common type of hearing aid is the bone conduction hearing aid, or the bone anchored hearing system, known as the BAHS. A bone conduction system is mainly an effective intervention for conductive or mixed losses, and is usually recommended in cases of chronic or irreversible conductive complications. It is also useful in cases of single sided deafness, as interaural attenuation loss through bone conduction between the two cochleas is $0 \mathrm{~dB}$, and therefore sound from one side can clearly be transmitted to the contralateral cochlea via the bones of the skull [23]. The device is composed of three parts; an external sound processor, an abutment, and a titanium implant. The titanium implant is surgically implanted into the bones of the skull, and through the process of osseo integration forms a structural connection between the bone and its surface. The abutment connects this titanium implant to the sound 
processor, which stimulates the implant and thereby stimulates the bones of the skull, which transmit the sound to both cochleae [23]. These are just a number of intervention options available to people with hearing impairment, and these all function to provide stimulation and sound to these individuals.

\section{Cochlear Implants}

A cochlear implant is an electronic medical device that replaces the function of the damaged inner ear. Unlike hearing aids, that usually make sounds louder, the cochlear implant bypasses the damaged inner ear to stimulate the nerves and electrically providing the sound signals to the brain. The evolution of cochlear implant has come a long way, since the beginning of its use over three decades ago. It has provided hope to patients with hearing impairment that cannot be corrected with use of hearing aids. By the end of the year 2012, around 324,200 registered implants had been implanted worldwide [24]. A cochlear implant consists of two parts, an internal implant that has the receiver and the electrode that is inserted into the cochlea and an external sound processor that sends the signal to the internal implant by means of magnetic conduction. Currently there are five companies that produce these devices, namely, Cochlear, Med-el, Advance Bionics, Nuerelec and Nurotron. Amongst these, the first three are the most widely used around the world and are approved by the Food and Drug Administration (FDA) in the US.

Each of the companies have a history in terms of development and innovation of the devices. They differ in various aspects and not just in the physical design, butalso in the software and options. For example, each of these differ in the number of channels they provide for stimulation, the coding strategies, the physical makeup of the electrode, as well as the speech processing strategies. A paper by Hainarosie, Zainea, and Hainarosie [25] discusses the history of these companies and the development of the cochlear implant in more depth. For the purpose of this master's thesis, however, this section aims to sufficiently outline the evolution in the field of Cochlear Implants for the three companies approved by the FDA in the United States of America; namely Cochlear Limited, MED-EL and Advanced Bionics.

\section{Cochlear Limited Implant Systems}

This was the company that came out with the first commercially available Cochlear Implant system in 1985. It was known as the Nucleus 22 and it was a device that had 22 electrodes. The external device was known as WSP (Wearable Speech Processor) and it used what was known as SPEAK processing strategy. The next generation of device from this company was the Nucleus 24 and was commercially available in 1997. Like the Nucleus 22, it also had 22 electrodes but in addition to this it had 2 extra cochlear reference electrodes. The external speech processor was called Sprint and used three processing strategies i.e. SPEAK, MSPEAK and CIS. One of the key features of this implant was that it had a removable magnet incase the implantee needed to undergo an MRI procedure.
The following generation came out in 1999. This was known as Nucleus 24 Contour. The major difference was in the electrode array, which was precurved and presumably easier to insert in the cochlea. The external processor also saw and evolution from the previously body worn device to Behind the Ear (BTE) device which seemed more like a normal hearing aid providing better comfort in wearing as well as better sound perception. This generation also saw an improvement in coding strategy whereby one more strategy was added. During the years up to 2002, the fourth and fifth generations of external processors were introduced with the last one being backward compatible with previous generation internal implants.

In year 2005, another model was introduced, known as Freedom. This had two types of electrode arrays which included one with a soft tip for a traumatic insertion. In 2008 Cochlear launched the hybrid model which incorporated the function of a conventional hearing aid as well. These are particularly useful for patients who have residual hearing. The Nucleus 5 was introduced in 2009. It was an improvement on the previous model and had a remote control as well for ease in programming. The current model available is Nucleus 6 . This is deemed to be the best model so far from this company and can be used with varieties of electrodes. Recently, Cochlear also introduced the Kanso. This is a single unit processor. It offers the same features as nucleus 6 and is more convenient and discreet.

\section{MedEl Corporation Implant Systems}

Medel made available its first commercial implant system in 1989. It introduced a 4 channel electrode array with an internal ceramic component. The sound processor used an analogue processing strategy. In 1991 the processor was updated with Behind the Ear (BTE) model. In 1994 they launched an 8 channel electrode internal implant known as Combi 40 and also introduced a new sound processor CIS PRO+ in 1995. The development of the internal component focused on the electrode array to be able to cover the entire cochlea for maximum stimulation. The following model, Combi 40+, also with ceramic casing had 24 active electrodes. During the time it was the thinnest available internal component at just $4 \mathrm{~mm}$. The main feature of this model was its MRI compatibility that was upto 1.5 Tesla without needing the magnet to be removed.

In 1999, Med-el introduced the Tempo+ which was a modular processor and could be used for infants. The Pulsar system was launched in 2004 with a variety of electrode options. In 2005 they launched the Duet sound processor which also had acoustic stimulation capabilities. In 2006, a new cochlear implant system was introduced. This was known as the Sonata. It was the first model that had a silicon casing for the internal implant. The year also saw introduction of various newer generation electrode arrays. The sound processor, known as Opus was also an improved version of the previous generations. It had improved electronics and had three coding strategies. In 2011, the Maestro system was introduced. It had five different 
types of electrode arrays. In addition to the Opus 2 processor, a single unit processor; Rondo was also introduced.

The latest version of their implant is the Synchrony, which has the thinnest internal component. The external processor, Sonnet also has many features that were not available in the previous generations including its water resistant capabilities. The main highlight of the synchrony however is the MRI compatibility. The synchrony is MRI compatible up to 3 Tesla and therefore does not require magnet removal.

\section{Advanced Bionics Company}

The first model from Advanced Bionics was introduced in 1996. Known as Clarion, it had a ceramic case for the internal component and a precurved electrode array with 8 electrodes. This had a body worn external processor. The S-Series processor was introduced a year later and had four coding strategies. The Clarion II was launched in 2001 with two type of sound processors, a body worn and a Behind the Ear (BTE). This also had 16 active electrodes. In 2003, the company introduced the HiRes $90 \mathrm{k}$ system which had a titanium casing. With this they introduced the Auria external sound processor. The company marketed another new generation of processor in 2006 known as Harmony with better coding strategy. The newest model from the company is Naida CI Q70 system. The internal component has three types of electrode arrays. With this a new sound processor; Neptune was introduced. This external processor is also water proof. Lately, all of the latest four sound processors (Auria, Harmony, Naida and Neptune) have come in modular variants: behind-the-ear, some-on-the-ear and nothing-on-theear [25].

\section{Cochlear Implant Candidacy}

The candidacy criterion for Cochlear Implants differs from one region to another depending on the level of the maturity of the Cochlear Implant program in the respective region. Regions where the Cochlear Implant program is just starting have stricter criteria, while those who have been implanting for a number of years, continue lowering the criteria for candidacy obviously in the interest of providing better life to the hearing impaired. The first child to be implanted with a cochlear implant was 10 years old. This happened in the 1980's. Over the years, with numerous research studies in this field, professionals have refined the candidacy criteria by exploring the pros and cons of the surgery and benefits of the outcomes. The technology has also evolved drastically over this period of time in terms of both the hardware and the software within the implants.

Cochlear Implants, being medical devices, are regulated in the respective countries. Each country differs from another in process of approving the same for use on humans. However, the candidacy criteria are more or less similar from the regulatory perspective from one region to another. In areas where regulations are not strictly enforced, one can find a variation from the outlined criteria. This is argued as a rational decision for improving the lives of those suffering from hearing impairment. The FDA divides the children candidates into two groups, one that is of age 12 months to 18 months and another of 18 months and older. Below are the criteria for each of these groups:

\section{i) Age 12 months to 18 months}

a) Bilateral profound hearing loss

b) Limited or no benefit with appropriate fit hearing aids

c) Lack of progress in auditory skill development

d) No physical contraindications for placement of the device

e) Medically cleared to undergo surgery

f) Realistic parental expectations and commitment to follow up appointments

ii) Age 18 months and older

g) Bilateral severe-profound hearing loss

h) Limited benefit with appropriate fit hearing aids

i) Lack of progress in auditory skill development

j) No physical contraindications for placement of the device

k) Medically cleared to undergo surgery

l) Realistic parental expectations and commitment to follow up [26].

There may arise situations where the above criteria cannot be followed strictly. Surgeons sometimes have to take decisions to implant for the best interest of their patients. One such situation is when the patient losses their hearing post meningitis, and the time to implant becomes of the essence, especially taking into account the progression of cochlea's ossification. Some clinics around the world also carry out implants for partial deafness or for candidates for whom they think Cochlear Implants will provide greater benefit and improved life than the hearing aids. Earlier, one of the criteria for candidacy for Cochlear Implants was bilateral severe to profound hearing loss. Over the years we have seen this situation change, with the criteria being updated as technology and surgical techniques evolved. Individuals with unilateral hearing losses are also implanted with Cochlear Implants. Those who have partial deafness are implanted with shorter electrodes to preserve the natural hearing that exists, or is still residual in the individual. There are also, as mentioned earlier, cochlear implants that are combination of an implant which stimulates electrically, but also include a part of it that functions as a hearing aid and provides acoustic amplification.

When it comes to a child candidate, it is imperative that parent expectations in relation to the outcome are realistic. 
Although there is no specific way to measure parent expectation, adequate counselling can help them make a better decision for their child, and also to aid them to adapt their expectations to reality. Families have to understand that the surgery is just a small part of the solution towards better life for their child and it is only the beginning of a long rehabilitation process that is yet to come, a process that will require their commitment and dedication to ensure good outcomes. It is generally accepted that children who have had prior experience with hearing aids perform better when implanted. This is regardless of whether hearing aids were useful or not as it may have provided some stimulation, even if the results of this stimulation were not apparent.

Another important factor to consider is the availability of rehabilitation facilities as near as possible to the location of the child, i.e. within the same city. Since rehabilitation is a long term process, travelling long distances to attend therapy session may become discouraging over time especially since the results of the therapy are not seen immediately. This is especially important in less economically developed countries, as rehabilitation centers may be only available in particular areas of the country, usually the more developed, urban areas. In these cases, it is remarkably important that the parents or guardians, and family of the child are committed to the child's rehabilitation and take a keen and active interest in ensuring its success. Rehabilitation centers can then train parents and provide them with home programs to go through with the child in cases of being unable to regularly attend the center, and these programs have to be followed vigilantly.

\section{Hearing with Cochlear Implants}

Jansen [27], in an article about cochlear implants, reported that when hearing with cochlear implants, sounds are different from the sounds produced by hearing aids. Being an implantee herself, she wrote that while hearing with hearing aids can be said to be passive i.e. sounds are simply amplified and delivered to the ear, hearing with cochlear implants can be described as active; you have to learn to hear with the implants [27]. Although she did not receive the implant in childhood, she provides an insight into how it is to hear with an implant, and highlights the difference between an implant and a hearing aid.

As discussed earlier, while hearing aids aim to stimulate the auditory nerve by amplifying sounds so that they are loud enough to be detected by the hair cells in the cochlea, cochlear implants bypass the damaged hair cells altogether and directly stimulate the auditory nerve. An implant, therefore, sounds different to a hearing aid, as hearing aids use acoustic stimulation, while cochlear implants provide electrical stimulation [24]. When an implant is programmed, each electrode is stimulated individually, first to find the lowest level of current needed to barely hear a sound, and then to find an upper level of stimulation, i.e. a level of current that is comfortably loud. At this stage, it is important to establish a good dynamic range of hearing and maintain loudness relationships between sounds while doing this [28].
While the cochlea has around 8000 inner hair cells responsible for detection of sounds and stimulation of the auditory nerve, most cochlear implants have around 22 electrodes, and therefore sound quality is inevitably different, due to the loss of the detail that the fine structures of the cochlea provide in normal, auditory hearing. An implantee therefore has to learn the patterns of sound that are stimulated by the implant's electrodes, and understand how to interpret them. Jansen [27] states, "At first, soon after receiving my cochlear implant, noises were just that -- noise. I was aware people were speaking, but I heard only sounds, not speech. I heard the changes in pitch, intonation and volume that go with speech, but I could not understand words without lip-reading." While patterns of speech and in other sounds will be picked up by the processor and transmitted electrically to the auditory nerve, the sounds have to be understood through constant use and active methods of learning in order to effectively hear with a cochlear implant.

This is simply a short insight into how hearing is made possible through a cochlear implant, and the differences between it and normal hearing. This highlights the need for effective rehabilitative programs, and is also crucial information for everyone involved in the cochlear implant process, especially parents, patients, teachers, and therapists. By understanding how the implant works, these faculties can not only have more realistic expectations of its outcomes, but also effectively plan rehabilitative measures according to this information.

\section{Chapter II: Outcomes of Cochlear Implants in Children}

\section{Speech Production and Spoken Language Skills}

The effect that hearing loss has on language and communication greatly affects an individual's life as previously stated, it can result in social isolation and exclusion, and have an impact on one's employability too. However, in pre-lingual children, or children still developing linguistic skills, a hearing loss can have an even greater effect, as it impacts the very development of language in a child. Language development in humans is theorized to occur in a variety of ways, and there are four prominent theories of language acquisition in children; the Nativist theory, the Interactionist theory, the Cognitive Developmental theory, and the Behaviourist theory [29].

The behaviourist theory, conceived by Skinner in 1957, is one of the earliest theories of language acquisition. It functions on the principle that children learn language orally from other humans, and utilize processes such as imitation, practice, and operant conditioning [29]. This theory states that language acquisition is dependent on human role models in the child's environment, and through stimulation of spoken language, the child learns and develops language. It also states that operant conditioning (rewarding the child with praise and affection upon correct imitation of oral language), plays a role in development. Critics of this theory argue that when a child isn't rewarded 


\section{Global Journal of Otolaryngology}

sufficiently, based on this theory, the child may not acquire language in the uniform way that it develops in humans.

They also argue that this theory does not account for the child's learning of abstract words [30]. However, for the purpose of this paper, the basis of this theory will be taken into consideration; the behaviourist theory has, in most parts, advanced in its assumptions about the acquisition of traditional grammar in native languages. It emphasized the role of verbal behavior in the learning of language, and although Skinner's model attributes development to the association of rewarding response to environmental stimuli, i.e. speech, it gives great importance to the presence of the stimuli. Children therefore are said to have a natural tendency towards learning the language of their social surroundings, and through a trial and error process, they develop the necessary skills for the production of correct language and grammar [31].

The nativist theory of language development followed the behaviourists' perspective on the acquisition of language, and was argued against by Noam Chomsky. An American linguist and psychologist, he argued that if language development was dependent on stimulation via the environment alone, a child could never acquire all the necessary tools for the endless learning of language, grammar, and semantics [32]. He therefore introduced the theory of Universal Grammar, stating that children are born with the innate knowledge of language, its systems, and their ability to develop it [33]. This innate knowledge, called the Language Acquisition Device, is claimed to be 'wired' in children's brains, and equips them with a set of intuitive tools for language development [33].

Nativism therefore suggests that all children have the same innateness that characterizes the grammar of the language they are going to learn to construct [34]. Although there are variations across languages, according to Chomsky, universal grammar operates on principles from which rules of every language are derived, not operating on different core principles for different languages [34]. A child's culture, environment, and the language it hears in its surrounds can be said to interact with its innate language acquisition device, and through interaction with limited input from the environment, an infant is able to use its innate tools to develop their knowledge and use of the intricacies of language [35].

The cognitive development theory was modeled by Jean Piaget, and was formed by four stages of cognitive development in infants that included the development of language. Piaget conducted a systematic study of development, and centered his theory around his observations of children's cognitive abilities [36]. The theory of cognitive development is therefore constituent of three components; the building of schemas, adaptation processes of assimilation and accommodation, and the four stages of cognitive development: the early sensorimotor period, the pre-operational stage, the concrete operational stage, and finally the formal operational stage [37]. In Piaget's theory, the use of language is developed in a similar way to other cognitive processes, and consequently infants display different types of language behavior depending on what stage of cognitive development they are at [38].

Piaget states thata child's language is firstegocentric, and then becomes social as it develops. This is because during the earlier stages of development, children find it difficult to understand different perspectives, and therefore do not work towards communicating for the purpose of interpersonal interaction [39]. This theory, however, also shows that development is still reliant on interaction with the child's environment, and therefore is subjected to criticism similar to that of Skinner's behaviourist theory [40]. Processes of assimilation and accommodation only occur as a child is corrected over his/her development, and can thus adapt correct mechanisms by utilizing cognitive abilities. A child would therefore develop language through these cognitive mechanisms if he/she has adequate interaction with language.

The fourth major theory of language development is the interactionist theory, which stresses the role of social interaction in the acquisition of language and the development of cognition [41]. This theory of cognitive development is also known as the Social Development Theory. Vygotsky's theory is based on the principle that an individual's development can't be fully understood without referring to sociocultural factors and context [42]. According to Vygotsky, language plays a fundamental role in cognitive development; it is the main method of communication of information from adults or role models to children, and it therefore is a powerful tool for intellectual adaptation [43]. Additionally, unlike Piaget, Vygotsky's interactionist theory believes that language and other cognitive processes, or thought processes, are initially separate. As speech develops, speech and thought become interdependent, and children then develop internalized inner speech, which is vital for cognitive development [42]. However, to develop this speech, a child must interact with the environment and with role models in order to learn and produce the linguistic abilities necessary for cognitive development, as outlined by this theory.

All four of these theories look at language development in infants, and although they provide different models for this development, they highlight language development as a significant process in human beings. Its importance for cognitive development can also not be understated, as shown by Vygotsky [44]. Therefore, for the purpose of this master's thesis, one can conclude that it is important for a child to be able to develop language, and in order to do so require input and interaction with the world. Whether one agrees Chomsky's theory of Universal Grammar or Skinner's behaviourist theory, development of speech and language is dependent on a child's being able to receive stimulation from its surrounding. It is for this reason that the ability to hear is vital, especially for young children who have not fully developed language. A child who is hearing impaired will not be able to pick up all the stimulation required 
for language development, and a child who is profoundly deaf will not receive stimulation at all as seen above, by Piaget's and Vygotsky's theories, this child's cognitive development would also be impacted, as language plays a great role in cognitive development.

\section{Factors Affecting Outcomes}

There are numerous factors that could potentially affect the language and quality of life for children with cochlear implants. These are important to take into consideration when studying the efficacy of cochlear implants, as certain variables tend to stand out as influential factors in deciding the outcomes for implantees. One such factor, believed to be the most important variable, is the time of implantation or the age at which intervention is introduced to the child [45]. It is important that children are implanted as close to the time of their impairment as possible, and therefore it is stressed that early implantation should be the norm. This is because it is important that children are not deprived of the auditory stimulation from the environment.

As we have seen previously, this stimulation from the environment spurs linguistic and cognitive development, and the longer that a child experiences a delay in this, the more apparent the effects of this delay will be. Additionally, when dealing with children, it is vital to note that children's brains are extremely plastic and therefore are especially receptive to development. If development does not occur at this stage, it requires more effort at a later stage. These statements are evidenced by studies showing that onset of deafness at later ages and shorter lengths of auditory deprivation have been associated with better speech perception scores [46], and so have younger implantation ages and longer implant use [47].

The critical period hypothesis for language acquisition highlights the urgency for intervention to take place as soon as possible, as delayed treatment may cause more permanent and lingering consequences, especially for a child's development [45]. The critical period is defined as a restricted developmental period during which the nervous system is particularly sensitive to the effects of experience [13]. In studies of congenitally deaf children, it has been seen that while normal hearing babies begin to babble at about 7 months, congenitally deaf children are deficient in this area. However, if they are exposed to alternative methods of expression, e.g. sign language, they 'babble' using this alternative method, in the case of sign language, they would 'babble' using their hands [13]. This supports the aforementioned definition of the critical period; a child is particularly sensitive to the environment, and his/her experience of that environment shapes its development.

Language acquisition therefore is hypothesized to occur primarily over this critical period, which ends at around the age of puberty [48]. Studies into the neuroscience behind this hypothesis have shown that during the critical period, infants are able to discriminate between and perceive all human speech sounds, and therefore are unbiased towards phonemes specific to certain languages. By 6 months of age, infants begin to show preferences for phonemes of their primary language. The bias towards the primary language grows as the child does, children can learn to speak a second language without an accent until the ages of 7 or 8 , after which the ease at which a child can pick up languages gradually declines [13]. However, it is imperative that a child needs to be exposed to the experience of language in the postnatal environment, in order to develop language during the sensitive critical period [13].

Comparative studies into the language abilities of children whose hearing impairment was identified by 6 months of age against the abilities of children whose impairment was identified after 6 months of age showed that the former group of children had significantly better language scores than the latter group. All children received intervention within around two months after their loss was identified, and the only variable that caused a significant difference in scores between the two groups was the age of identification and intervention [49]. This highlights the importance of early intervention and implantation, especially in congenitally deaf children, in order to make the utmost use of the critical period, and provide the necessary experience for appropriate development.

A study by Ann Geers into children with early cochlear implantation (2002) involved a sample of 136 children in the United States with a mean age of 9 years at test and 3 years 6 months at implantation who participated in this study, which aimed to investigate factors/variables that contribute to speech and language outcomes in prelingual children with cochlear implants. The results of this study showed that children with implants before 5 years of age are enabled to interact with the auditory information necessary for the development of language and speech at a crucial age for development. The variables that can have an effect on development at this age have been categorized into three varieties of factors; what a child brings to the learning environment, what is provided by the implant, and what is provided by the rehabilitative program, the parents and the professionals.

The factors categorized as being something brought by the child to the learning environment by this study by Geers [28] include nonverbal intelligence, which was found to be the most important characteristic. Other variables studied included age at implant, age at onset of deafness, and periods of normal hearing. Additionally, another variable that presents itself in cases of cochlear implants is the child's prior development before the onset of hearing impairment, as post-lingual children may have better speech outcomes due to already being in the process of developing speech and language, while pre-lingual children may require more rehabilitative effort in order to stimulate the adequate development of language [28].

Factors that involve the cochlear implant device and technology itself also play a major role in contributing towards the development of speech and language in implanted children, 
as the implant needs to be functioning optimally to best support development. The use of an updated coding strategy had an impact on the outcome areas examined by this study, which noted that it is important that children are able to access the technological and engineering advances in speech processing. The data of this study outlines the benefits of improved technology, as it is associated with better outcomes. A larger number of active electrodes on the implant map is also associated with better outcomes, a complete electrode insertion, along with a map that activates all of these electrodes allow for optimal performance in stimulation, which nurtures development. A well fitted map also plays an important role in potentially positive outcomes, and is shown to be particularly important in newly implanted infants [28].

The third group offactors relates to the nurturing environment provided to the child by the parents, the professionals involved, and the rehabilitative program adopted. Communication mode was evidently most important in this group of factors, with better outcomes in children whose programs emphasized the use of audition and speech in communication, over non oral means [28]. Parents and guardians play an important part in the rehabilitative process of a child, a role that cannot be emphasized enough. By striving for a consistent emphasis on the development of speech and auditory skills in their children through active involvement and participation in rehabilitative programs, speech therapy sessions, and in interacting with their children throughout the day, the family of an implantee can be a valuable factor towards successfully meeting goals for development.

The role of the clinicians and professionals involved is also vital, as active involvement in the rehabilitation of an infant is necessary for successful rehabilitation programs. As stated in the above paragraph, it is important to have an accurate and well fitted map for the child, and therefore the clinician mapping the child's implant must be aware of how to best implement this. The professionals involved in education programs, speech therapy sessions, and other such rehabilitative measures are key in ensuring that children within these programs get the best out of them, and that they are provided with adequate resources to meet goals and have positive outcomes in speech, language, and cognitive development.

\section{Rehabilitation of Children with Cochlear Implants}

The importance of rehabilitation cannot be overemphasized for children who get cochlear implants. The time between the onset of hearing loss and intervention with cochlear implants is very important as seen previously in this master's thesis. The length of auditory deprivation is a critical factor that determines how easy or difficult rehabilitation will be. Considering this factor and other influential factors, it is upon parents to decide on the type of rehabilitation that will be most suitable to achieve the best outcome for the children. This decision and course of action is usually discussed with the speech therapist and a program is prepared on how to rehabilitate the child. The aim of rehabilitation, especially for children, is to work towards making sure that younger children who are implanted before or around school age are mainstreamed. When it comes to the choice of rehabilitation method, there are three main pathways that can be adopted as described below:

I. Auditory Verbal Therapy: In this approach the emphasis is placed on the auditory skills development of the child with the implant. Children are encouraged to learn to listen and develop spoken language without the need to rely on sign language or lip reading. The speech therapist coaches and guides the parents on ways to encourage development of listening skills in everyday situations. The primary goal of AVT is to develop spoken language through the use of listening and integration into the hearing community. The academic development goals for the children are to develop their skills so that they are mainstreamed.

The language development in children occurs through early, consistent and successful use of their implants so that they develop listening, speech and spoken language following natural development patterns. Parents involvement in the process is the key to determining the outcomes. Family members are encouraged to attend therapy sessions so that the therapist can coach and guide them how to develop such skills in everyday situations. It also involves a lot of play and role play activities as part of the therapy process.

I. Auditory Oral Approach: This method encourages children to develop spoken language through use of both verbal and non-verbal means, including lip reading. The primary goal once again is to enable children to develop spoken language and communication skills that are necessary for their integration into the hearing community. Academically, the aim is to encourage development of skills that will ensure successful mainstreaming. The language development using this method is through early, consistent and successful use of their cochlear implants accompanied by lip reading. As with AVT, this approach also requires a commitment from parents and family members.

They have to work closely with the therapist to try and stimulate the child's spoken language development by various means during the child's day. It is important to understand that therapy, whatever approach selected, is a long process, and parents and family members have a big role to play in development of spoken language for the child. Family members and parents have to be active participants in the therapy sessions so that they can provide the child optimal speech and language stimulation according to the level of the child.

II. Total Communication: This approach encourages using every and all means to communicate. The child is exposed to a formal sign language, finger spelling, natural gestures, lip reading and spoken language. There may be other means of communication or any aid that helps in communication. The 
idea of this approach is to communicate and teach in any manner that works, and the child is encouraged to use a combination of communication methods e.g. speech and sign. The primary goal is to provide an easy and less restrictive communication method for the child and their parents, family, friends and peers. Such approach may be suitable especially if the child is struggling to develop expressive spoken language which may be due to other associated issue such as weakness, cerebral palsy or simply due to cognitive or processing difficulty.

The child undergoing total communication therapy develops language that may be spoken or combination of spoken and signing or another method. Commitment from family and parents is encouraged, especially for family members to learn the sign language chose for the child to ensure that there is no breakdown of communication between them and the child. The family members are encouraged also to visit the therapist with the child. However, in addition to the speech therapist, there may be requirement to see other professionals depending on the associated issues that the child has e.g. physiotherapist, occupational therapist, teacher etc. From the above, we can establish the importance the parents and family members have in the rehabilitation of the child no matter what approach is chosen to develop their communication skills. Some children with cochlear implants may also have additional special needs that will require an even stronger commitment by the parents and family members.

\section{Chapter III: Conclusion}

The importance of the sense of hearing in human life cannot be stressed enough. Sounds play a major role in everyday life, in a variety of ways and in innumerable situations. They allow us to communicate with each other through speech and spoken language, essentially the use of sounds to communicate our thoughts through a mutually understood mechanism. Our awareness of the environment also relies on our hearing, keeping us alert to danger in our surroundings essentially all the time, warning us of vehicles like cars and buses, of insects or animals that may be harmful, and of sounds produced by mechanical objects, to name a few. As studied in the previous section, the stimulation of our neural systems by sounds plays an important role in our cognitive development, and we learn and shape our learning through the stimulation from our senses.

Therefore, having looked at the importance of hearing and sounds, it can be disadvantageous in many aspects to miss out these benefits. There are a number of risks that can be associated with hearing impairment, including social isolation, stress, anxiety, prone to accidents (due to loss of environmental awareness), cognitive decline, and psychological issues, to name a few. Analysis of the studies discussed in this master's thesis and numerous other studies conducted worldwide provide two imperative factors to reduce the effects of hearing impairment on an individual's life; identification and diagnosis of a hearing loss as close to the time of its occurrence, and the introduction of intervention and rehabilitative measures as close to the time of diagnosis as possible. This is so as to minimize the time an individual is deprived of stimulation to the auditory system and the brain as much as possible.

In cases of congenital hearing loss from birth, or hearing loss that occurs close to the time of birth i.e. early in a child's life, it is even more important that intervention is introduced not long after the identification of the impairment. Newborn hearing screening programs are therefore very advantageous in this process, as they allow the diagnosis of hearing loss shortly after birth, and therefore opens the opportunity for an early intervention. While hearing aids are routinely used to manage a hearing loss, the advent of cochlear implants allowed for a world of possibilities in rehabilitation of the profoundly deaf. However, while cochlear implants can provide sensitivity to sounds for implantees, the role of rehabilitative programs and everyone involved in the rehabilitation of an infant should not be taken lightly. These can be definitive factors in the efficacy of any rehabilitative programs, and in attaining successful outcomes in areas of speech and language development, along with a better quality of life.

Therefore, it is imperative that all these factors are acknowledged and addressed when researching cochlear implants and studying their outcomes. It is also vital that one is aware of the role of hearing in life, and thus aware of the importance of striving for successful outcomes in infants implanted with these devices, especially in countries that have not had ready access to these services, Tanzania being such a country.

\section{Chapter IV: Goals}

\section{The Aim of this Thesis}

The aim of this thesis is to evaluate the outcomes of rehabilitation of children with cochlear implants in Tanzania and try to establish the main factors that may influence these outcomes. Cochlear Implants are fairly new to Tanzania. They have become more known in the last 5 to 7 years only. There was no local Cochlear Implant program in place in either the public or private healthcare services in the country. It is only since 2014 that efforts to mobilize a local CI program started, and first local Cochlear Implant surgeries are expected to take place in June 2017. At the time of conducting this research, Tanzania already had about 30 children cochlear implantees. The children were aged between 1.5 years and 7 years (age at implantation). All of the implantees were implanted outside Tanzania, mostly in India.

Children have been implanted with devices from all 3 major U.S. FDA approved manufacturers [50], however over 75\% have been implanted with MED-EL devices. Almost all of the implants have been done through government sponsorship and referral. For this matter, most of the children have been implanted unilaterally. Regarding rehabilitation facilities, there is one 
private clinic that offers Speech Therapy services; HearWell Audiology Clinic, which was established by me in late 2011. This has been elaborated further in the biographical section of this thesis. There is also the main referral hospital (Muhimbili National Hospital) that has a rehabilitation unit for speech. The research was conducted at this private center as almost all of the implantees have been visiting the center for speech therapy and support for their Cochlear Implant devices.

There is a lack of expertise in the field of cochlear implants and it is only at this private center that the staff are qualified to deal with cochlear implant devices in terms of rehabilitation and troubleshooting [51-56]. HearWell Audiology Clinic has a work force of 5 full time staff including myself, my colleague who is an Audiologist and Speech and Language Pathologist, and 3 qualified nurses, one of whom is a receptionist and customer service representative and the other two who have undergone rehabilitation courses offered by Med-El on rehabilitation of children with Cochlear Implants. This course comprises of 8 modules and covers rehabilitation for all age groups, from toddlers to adults, as well as children with special needs who have been implanted. These two staff assumes the role of assistant speech therapists and are countinuously trained in house by my colleague.

Data for about 30 implantees was available, and below is the graphical representation of the age at implantation for these children: From the above figure 1, it can be noted that the intervention in these children was quite late. A majority of the children who were implanted were of ages 2 to 5 years, and all implantees were pre-lingual. Just a glimpse at the chart tells us of the immense rehabilitation work that is required for these children. In a limited resource setting, this becomes even more challenging. However, despite these challenges, we managed to ensure that the children get most of what is available in terms of rehabilitation and support. With regards to the spare parts and mapping, initially we started collaborating with centers where the children were implanted (India) and facilitated the availability of spare parts however the children still had to travel to India for mapping. This was also an additional challenge, as it meant additional costs for the patients, resulting in delays of keeping mapping appointments due to financial and time constraints.

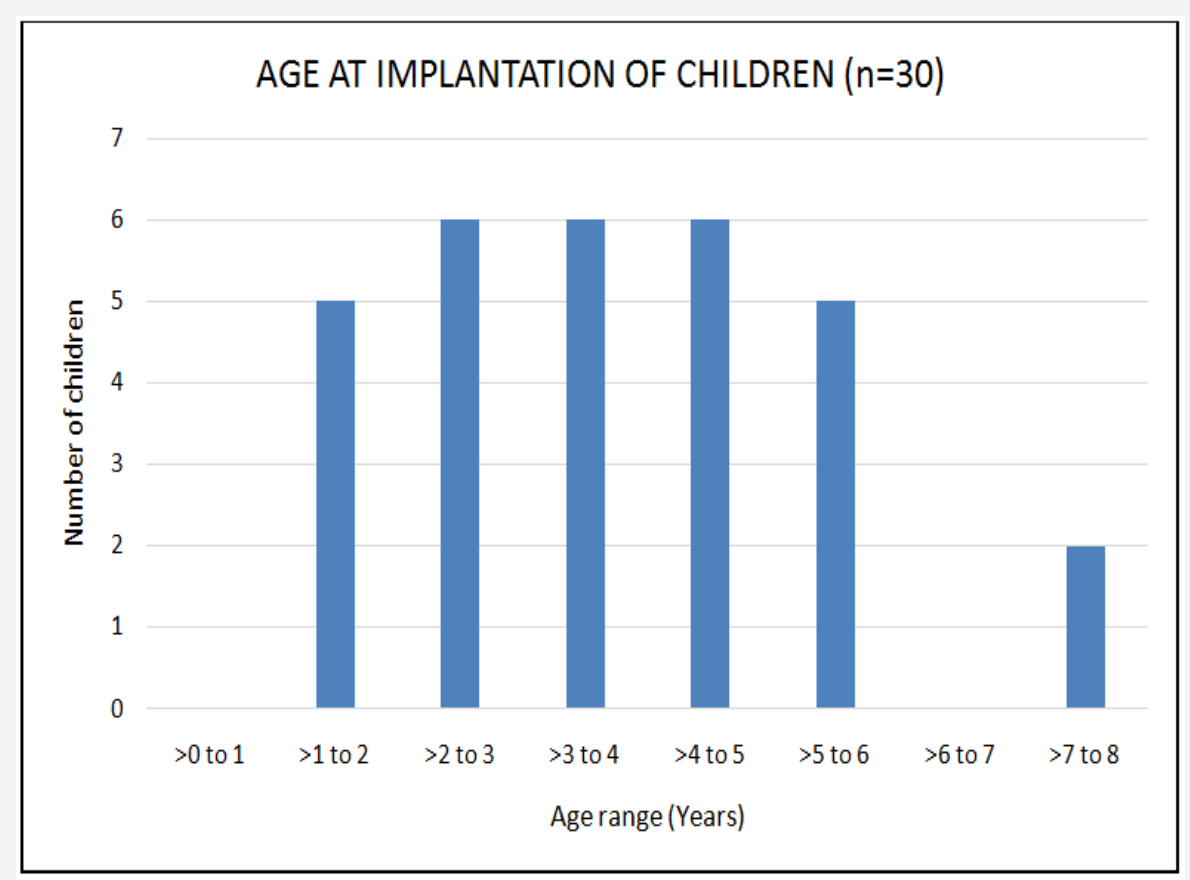

Figure 1: Graph showing the age at implantation for the 30 children for whom data was available for the purpose of this study.

This changed when HearWell became the official distributor of MED-EL in Tanzania in mid-2014. The patient support process became better organized, and a direct link was established with the company headquarters in Innsbruck, resulting into quick turnaround times for repairs and spare part support. Local mapping services were also established at this center and patients did not need to travel to India anymore. This did not just reduce the cost and time burden for the parents, but also meant that better results could be predicted due to ease of accessibility of services locally.
Chapter V: Methods

\section{Participants}

Table 1.

\begin{tabular}{|c|c|}
\hline Age (Years) & No. of Children \\
\hline$>1-2$ & 3 \\
\hline$>2-3$ & 3 \\
\hline$>3-4$ & 3 \\
\hline$>4-5$ & 3 \\
\hline$>5-6$ & 3 \\
\hline
\end{tabular}




\section{Global Journal of Otolaryngology}

15 participants were chosen for this study, with ages as follows: (Table 1) from the above, two children of ages 1 to 2 years were bilateral implantees. Their inclusion in this study allowed all age groups to have $\mathrm{n}=3$ participants, providing more data for the discussion of the factors that could influence cochlear implant outcomes. The implantees were divided into two groups; Group 1 was comprised of the children who

Table 2: Table showing the number of children in each group, and their ages. Group 1 consists of children attending $\geq 3$ sessions weekly, while Group 2 consists of children attending about one session a week.

\begin{tabular}{|c|c|c|c|}
\hline \multicolumn{2}{|c|}{ Group 1 } & \multicolumn{2}{c|}{ Group 2 } \\
\hline Age (years) & No. of children & Age (years) & No. of children \\
\hline$>1-2$ & 2 & $>1-2$ & 1 \\
\hline$>2-3$ & 1 & $>2-3$ & 2 \\
\hline$>3-4$ & 1 & $>3-4$ & 2 \\
\hline$>4-5$ & 1 & $>4-5$ & 2 \\
\hline$>5-6$ & 0 & $>5-6$ & 3 \\
\hline
\end{tabular}

These children and their parents/guardians however, are usually given a 'home program' to administer at home but were omitted from the study due to lack of consistency in follow up and to minimize assumptions on effectiveness of the rehabilitation. Data from this group would also be less reliable, as outcomes cannot be consistently assessed by the clinicians. attended speech therapy sessions at least 3 times a week $(n=5)$, and Group 2 of the children who attended speech therapy once a week, more or less $(n=10)$. The number of implantees in each age group was not intentionally planned, but rather occurred due to the attendance to rehabilitation sessions. Other children, due to their geographical location (away from main city) could not attend speech therapy sessions frequently.
The groups included in the study were as follows: Table 2 . The time frame for the purpose of this research study was 1 year of hearing age for all participants i.e. one year after switch on of the implant and the fitting of the processor. It should be noted that the children were implanted at different times/years [57-60].

\section{Cochlear Implant Program - Children's Implant Profile (ChIP - modified)}

Date of Team Review.

Date(s) of Evaluations A ge at Onset of Hearing Loss:

School Placement:

\begin{tabular}{|c|c|c|c|}
\hline $\begin{array}{l}\text { TEAM IMPRESSIONS OF THE FACTORS IMPORTANT } \\
\text { TO IMPLANT USE AND SU CCE SS }\end{array}$ & $\begin{array}{c}\text { NO } \\
\text { CONCERN }\end{array}$ & $\begin{array}{c}\text { SOME } \\
\text { CONCERN }\end{array}$ & $\begin{array}{c}\text { GREAT } \\
\text { CONCERN }\end{array}$ \\
\hline 1. OTOLARYNG OLOGY & & & \\
\hline (1) Medical evaluation/Physician concerns & & & \\
\hline ( Radiological & & & \\
\hline 2. AUDIOLOGY & & & \\
\hline Test Reliability & & & \\
\hline (1) Attention/behavior & & & \\
\hline 口 Hearing Aid Use & & & \\
\hline Compliance with Recommendations & & & \\
\hline $\begin{array}{ll}\text { Hearing Aid Benefit } \\
\text { Auditory Skills (given CA and duration of deafness) }\end{array}$ & & & \\
\hline Other Disabilities & & & \\
\hline 3. SPEECH PATHOLOGY & & & \\
\hline Receptive L anguage & & & \\
\hline (1) Expressive L anguage & & & \\
\hline Play/social Skills & & & \\
\hline Oral motor Skills & & & \\
\hline$\square \quad$ Speech Reading Skills & & & \\
\hline 口 Communicative Intent & & & \\
\hline ( Speech Production & & & \\
\hline (1) Attention/behavior & & & \\
\hline - Chronological age/duration of deafness & & & \\
\hline 口 Other Disabilities & & & \\
\hline 4. SOCLAL WORK & & & \\
\hline [ Family Structure \& Support & & & \\
\hline (1) Attention/Behavior & & & \\
\hline 口 Expectations (Parent Child) & & & \\
\hline Other Disabilities & & & \\
\hline 5.EDUCATION & & & \\
\hline a Current Educational Placement & & & \\
\hline 口 Class conducive to implant use & & & \\
\hline 口 Availability of Support Services & & & \\
\hline a Appropriateness of Skills of Service & & & \\
\hline Q Educational Staff CI Training & & & \\
\hline Future Placement & & & \\
\hline [ Parent's ability to participate in education process & & & \\
\hline 口 Child's ability to participate in education process & & & \\
\hline
\end{tabular}

Appendix I: children's implant profile (chip) 


\section{Global Journal of Otolaryngology}

\section{Procedure}

It is worthy to mention that all forms of assessment used for this purpose were obtained from Med-el. This is due to the fact that we do not have standardized assessment material and rehabilitation material specifically for Tanzania. Med-el guidelines and forms were found to be the most appropriate to be used regardless of the choice of implants by the parents for their children. Before going abroad for surgeries, initial assessments were done for Cochlear Implant candidacy of the children using the CHIP evaluation (Children's Implant Profile), the sample form can be found on Appendix I. This ensured that the implantees did not have any contraindication for surgery and did not have any other special needs. Since most children were government sponsored and it was the beginning of the Cochlear Implant surgery referral program, the candidacy criteria were quite strict; i.e. only children with severe to profound hearing loss, aged less than 7 years with no additional handicap or contraindications for surgery were selected. Due to limited funding for this program, higher preference was given to the lower age groups.

All children who received cochlear implants started speech therapy one month posts witch-on at the local center (HearWell Audiology Clinic). The speech therapist used Auditory Verbal
Therapy (AVT) as the rehabilitation method. All implantees followed the same course. The older children had however already developed some form of sign language to communicate with their parents and families. This mode of communication was not a formal sign language, but a way of communication between the children and their families informally. They would use gestures to express themselves [61-64].

All of the children who underwent the Cochlear Implant Surgery had hearing aid trials of 6 months or more and therefore compliance was not a major issue during the rehabilitation process. Both groups were given the Little Ears Diary to fill in the observations and progress by the parents for each week of progress since switch on. Regular progress was noted down by the clinic informally after each session for both groups. At the end of 1 year hearing age the following evaluation forms were administered:

i. Little Ears Auditory Questionnaire (LEAQ) (Appendix I \& II)

This evaluation was done for each child regardless of the group and the scoring was noted.

ii. Meaningful Auditory Integration Scale (MAIS) (Appendix III \& IV)

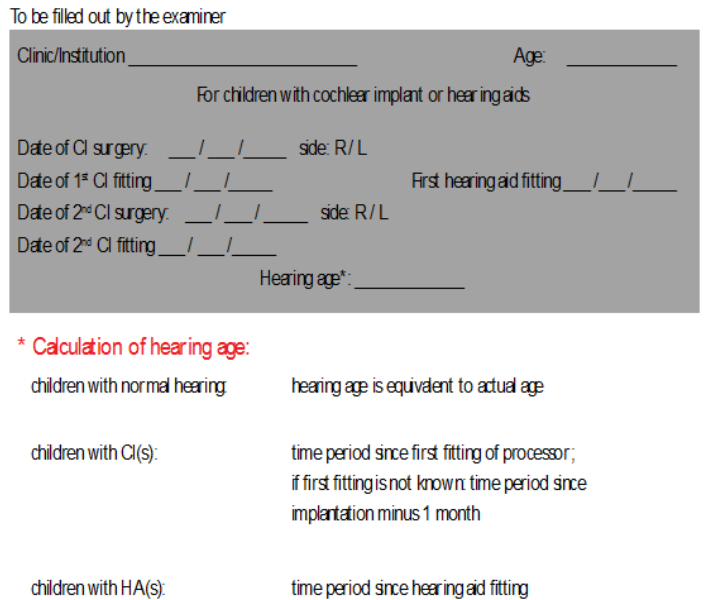

Additional quesions we are interested in:

1. Hare you observed any responsesto sound or voices in your child that are not included in the questionnaire?

2. Hare you noticed any surpising responses to sound or voices in your child recertly or in the las $1-2$ weeks (i.e. con helshe do this arready?

Thank You for completing the LittlEARS auditor y questionnaire!

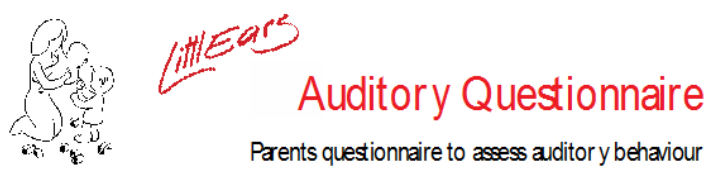

F. Coninx, V.Weichbold, L.Tsiakpini

Gode_

Thisauditoryquestiornare isdesgned to wsesstheauditory development inheaing and heringimpared children ater cochler implattaion (Cl) or heringad $(\mathrm{HA})$ fittinglt covers aditory development in the first two years after $\mathrm{Cl}$ or $\mathrm{HA}$ supply (up to hering ae 2 yers) or in hearing children up to two yeers of ae. The questionare includes age-dependent questions with increasing complexity of the auditory responses Therefore, with ayounger child, fever questions will be answ ered "yes"

How to complete the questionnaire?

All questions are to be answered by circling either YES or NO. Pleæemak

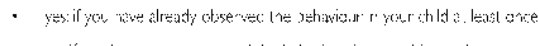

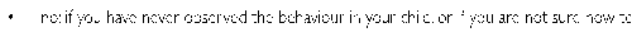
answer the question.

If you answer 6 questions with " $\mathrm{no}$ " for hering children, you do not næed to cortinue the questiomare. These questions will then be regaded $\mathrm{s}$ " $\mathrm{no}$ " answers

For children fitted with aCl(s) or $\mathrm{HA}(\mathrm{s}$ ), all questions should be answered, since they may show auditory behaiour covered by later questions 
Global Journal of Otolaryngology

\begin{tabular}{|c|c|c|c|}
\hline & Auditory Response & Answer & Example \\
\hline & Does your child respond to a familiar voice? & Jyes Jno & $\begin{array}{l}\text { Smiles; looks towards source; talls } \\
\text { animatedly }\end{array}$ \\
\hline 2 & Does your child listen to somebody speaking? & Jyes Jno & $\begin{array}{l}\text { Listens; watts and listens looks at } \\
\text { the speaker for a longer time }\end{array}$ \\
\hline & $\begin{array}{l}\text { When somebody is speaking, does your child } \\
\text { tum hisher head towards the speaker? }\end{array}$ & Jyes J no & \\
\hline 4 & $\begin{array}{l}\text { Is your child interested in toys producing } \\
\text { sounds or music? }\end{array}$ & Jyes $\Xi$ no & Rattle, squeezing toy \\
\hline 5 & $\begin{array}{l}\text { Does your child look for a speaker helshe } \\
\text { cannot see? }\end{array}$ & Jyes $\beth$ no & \\
\hline 6 & $\begin{array}{l}\text { Does your child listen when the radia/CD } \\
\text { playertiape player is tumed on? }\end{array}$ & Jyes Јno & $\begin{array}{l}\text { Listening tums towards the sound, } \\
\text { is attentive, luughs or singsitalls } \\
\text { "along" }\end{array}$ \\
\hline 7 & Does your child respond to distant sounds? & Jyes Jno & $\begin{array}{l}\text { When being called from another } \\
\text { room }\end{array}$ \\
\hline 8 & $\begin{array}{l}\text { Does your child stop crying when you speak } \\
\text { to himher without him her seeing you? }\end{array}$ & Jyes Jno & $\begin{array}{l}\text { You try to comfort the child with } \\
\text { a soft voice or song: Without eye } \\
\text { contact. }\end{array}$ \\
\hline 9 & $\begin{array}{l}\text { Does your child respond with alarm when } \\
\text { hearing an angry voice? }\end{array}$ & Jyes Jno & Becomes sd and starts crying \\
\hline 10 & Does your child "recognise" acoustic nituals? & Jyes J no & $\begin{array}{l}\text { Musical box by bed, lullaby, water } \\
\text { running into the tub }\end{array}$ \\
\hline & $\begin{array}{l}\text { Does your child look for sound sources } \\
\text { located at the left, night or back? }\end{array}$ & Jyes Jno & $\begin{array}{l}\text { You call or say something, the dog } \\
\text { barks etc. and the child looks and } \\
\text { finds the sources }\end{array}$ \\
\hline 12 & 2 Does your child react to hisher name? & Jyes J no & \\
\hline & $\begin{array}{l}\text { Does your child look for sound sources } \\
\text { located above or below? }\end{array}$ & Jyes Jno & $\begin{array}{l}\text { A dock on the wall, or something } \\
\text { falling on the floor }\end{array}$ \\
\hline & $\begin{array}{l}\text { When your child is sad or moody, can helshe } \\
\text { be calmed down or influenced by music? }\end{array}$ & Jyes Jno & \\
\hline & $\begin{array}{l}\text { Does your child listen on the telephone and } \\
5 \text { does helshe seem to recognise that somebody } \\
\text { is talking? }\end{array}$ & Jyes Jno & $\begin{array}{l}\text { When grandma or daddy calls, } \\
\text { the child takes the receiver and } \\
\text { "listens" }\end{array}$ \\
\hline & $\begin{array}{l}\text { Does your child respond to music with } \\
\text { inythmical movements? }\end{array}$ & Jyes コno & $\begin{array}{l}\text { The child moves amsllegs to the } \\
\text { music }\end{array}$ \\
\hline & $\begin{array}{l}\text { Does your child know that a certain sound is } \\
\text { related to a certain object or event? }\end{array}$ & Jyes $\Xi$ no & $\begin{array}{l}\text { The child hears the sound of an } \\
\text { aeroplane and looks towards the shy. } \\
\text { or hears a car and looks towards the } \\
\text { street }\end{array}$ \\
\hline & $\begin{array}{l}\text { Does your child appropriately respond to } \\
\text { short and simple remarks? }\end{array}$ & Jyes $\amalg$ no & "Stop" "Yude" "Dont" \\
\hline
\end{tabular}

\begin{tabular}{|c|c|c|c|}
\hline & Auditory Response & Answer & Example \\
\hline 19 & $\begin{array}{l}\text { Does your child respond to "No" by typically } \\
\text { interupting hisher current activity? }\end{array}$ & Jyes Jno & $\begin{array}{l}\text { A strongly pronounced "na, no." } \\
\text { - athough the child does not see } \\
\text { you (?) - is effective }\end{array}$ \\
\hline 20 & Does your child know family members' names? & Jyes Ino & $\begin{array}{l}\text { Where is _.daddy, mummy, } \\
\text { Mark,.. }\end{array}$ \\
\hline 21 & Does your child imitate sounds when asked? & Jyes J no & “Ааa","000","iil' \\
\hline 22 & Does your child follow simple commands? & Jyes $\Xi$ no & $\begin{array}{l}\text { "Come here"';"Take off your } \\
\text { shoes"" }\end{array}$ \\
\hline 23 & Does your child understand simple questions? & Jyes $\amalg$ no & $\begin{array}{l}\text { "Where is your tummy?';" Where } \\
\text { is daddy?" }\end{array}$ \\
\hline 24 & Does your child bring items when asked? & Jyes J no & "Bring me the ball"' etc. \\
\hline 25 & $\begin{array}{l}\text { Does your child imitate sound or words you } \\
\text { say? }\end{array}$ & Dyes J no & "Say. woof woof";" "Say.c-a-rer" \\
\hline$\gamma_{0}$ & $\begin{array}{l}\text { Does your child produce the right sound to } \\
\text { a toy? }\end{array}$ & Jyes J no & "Vurm" with car," "moo" with cow \\
\hline 27 & $\begin{array}{l}\text { Does your child know that certain sounds go } \\
\text { with certain animals? }\end{array}$ & Jyes $\square$ no & $\begin{array}{l}\text { Woof woof }=\text { dog meow }=\text { cat; } \\
\text { cock-a-doodle-do = cockerell } \\
\text { rooster }\end{array}$ \\
\hline 28 & $\begin{array}{l}\text { Does your child try to imitate environmental } \\
\text { sounds? }\end{array}$ & Jyes $\sqcup$ no & $\begin{array}{l}\text { Animal sounds, sounds of } \\
\text { household appliances, police car } \\
\text { siren }\end{array}$ \\
\hline$n$ & $\begin{array}{l}\text { Does your child correctly repeat a sequence } \\
\text { of short and long syllables you have said? }\end{array}$ & Dyes Jno & "la-la-laa" \\
\hline & $\begin{array}{l}\text { Does your child select the right object from a } \\
\text { number of objects when asked? }\end{array}$ & Jyes Ino & $\begin{array}{l}\text { You are playing with toy animals } \\
\text { and ask for "the horse";you are } \\
\text { playing with coloured balls and ask } \\
\text { for the "red ball" }\end{array}$ \\
\hline & $\begin{array}{l}\text { Does your child try to sing along when hearing } \\
\text { a song? }\end{array}$ & Jyes J no & Nursery hymes \\
\hline & $\begin{array}{l}\text { Does your child repeat certain words when } \\
\text { asked? }\end{array}$ & Jyes J no & "Say Hello' to grandma" \\
\hline 33 & Does your child like being read to? & Jyes J no & From book or piture book \\
\hline & Does your child follow complex commands? & Jyes Јno & $\begin{array}{l}\text { "Take your shoes off and come } \\
\text { here" }\end{array}$ \\
\hline & Does your child try to sing with famTar songs? & Jyes J no & Lullaby \\
\hline
\end{tabular}

Total score $=$ all questions ticked $w$ ith

"ves"

Appendix III: meaningful auditory integration scale (mais).

\section{Appendix IV.}

LEVEL 1 \& LEVEL 2

MEANINGFUL AUDITORY INTEGRATION SCALE (MAIS)

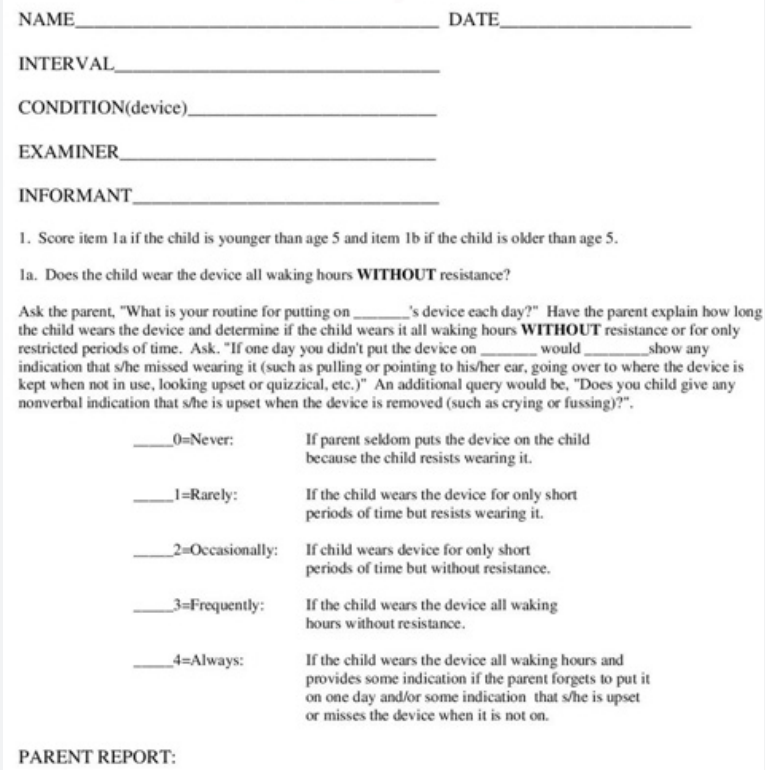

PARENT REPORT: 
Ib. Does the child ask to have his or her device put on, or put it on him/herself WITHOUT being told?

Ask "What is "s routine for putting on his/her device each day?" Have parent explain if it is the parent or the child who takes responsibility for it. Ask, "If one day, you didn't put the device on and didn't mention it, would___ ask to wear it and be upset by not having it?" An additional query would be, "Does your child basically wear it according to routine (such as all day at school and one hour at night) or does s/he want it on all waking hours?" (for example, she puts it on at night even after his/her bath)? The latter would indicate a child who is more boded and dependent on his her device than the former.

\begin{tabular}{|c|c|}
\hline $0=$ Never: & If the child resists wearing it. \\
\hline 1=Rarely: & $\begin{array}{l}\text { If the parent says child wears it without resistance, } \\
\text { but would never ask for it. }\end{array}$ \\
\hline $2=$ Occasionally: & $\begin{array}{l}\text { If child might inquire about it and is content to wear } \\
\text { it with a set time routine. }\end{array}$ \\
\hline 3=Frequently: & $\begin{array}{l}\text { If the child wears the device all waking hours without } \\
\text { resistance. }\end{array}$ \\
\hline 4=Always: & $\begin{array}{l}\text { Only if child wears it all waking hours and it's part of } \\
\text { his body (like glasses would be). }\end{array}$ \\
\hline
\end{tabular}

PARENT REPORT:

2. Does the child report and/or appear upset if his/her device is non-functioning for any reason?

Ask parent to give examples of what the child has done (verbally or nonverbally) when the device was not working. Ask also, "Have you ever checked ___ 's device and found it was not working (or headpiece had fallen off), but s/he had not noticed or had not told you?" In the case of the younger child, ask "Have you ever checked device and found it wasn't working but s/he had not provided any nonverbal indication (such as crying, reaching for the headpiece, etc.) that it was not working?"

\begin{tabular}{|c|c|}
\hline $0=$ Never: & $\begin{array}{l}\text { If child has no awareness of the device working or } \\
\text { not. }\end{array}$ \\
\hline 1=Rarely: & $\begin{array}{l}\text { If parent says child might only notice a } \\
\text { malfunctioning device (using verbal or nonverbal } \\
\text { indication) once in a while. }\end{array}$ \\
\hline $2=$ Occasionally: & $\begin{array}{l}\text { If parents can give some examples of when the child } \\
\text { would recognize a malfunctioning device (or if } \\
\text { headpiece has fallen off) more than } 50 \% \text { of the time } \\
\text { and may be beginning to distinguish some device } \\
\text { problems from others. }\end{array}$ \\
\hline $3=$ Frequently: & $\begin{array}{l}\text { If parent gives examples and/or child can often } \\
\text { distinguish different types on malfunction (e.g. bad } \\
\text { cord vs. weak batteries). }\end{array}$ \\
\hline 4=Always: & $\begin{array}{l}\text { If child would never go without immediately } \\
\text { detecting and reporting a problem with his/her unit } \\
\text { and can easily identify what the problem is. }\end{array}$ \\
\hline
\end{tabular}

\section{PARENT REPORT:}


3. Does the child spontaneously respond to his name in quiet when called auditorially-only with no visual cues?

Ask, "If you called ___ 's name from behind his back in a quiet room with no visal cues what percentage of the time would he respond the first time you called?"

1=Never: If the child never does.
1=Rarely: $\quad \begin{aligned} & \text { If he has done it only once or twice or only with } \\ & \text { multiple repetitions. }\end{aligned}$
2=Oecasionally: $\begin{aligned} & \text { If he does it about } 50 \% \text { of the time on the first trial or } \\ & \text { does it consistently but only when parent repeats his } \\ & \text { name more than once. }\end{aligned}$
4=Always:

PARENT REPORT:

4. Does the child spontaneously respond to his name in the presence of background noise when called auditorially only with no visual cues?

Ask, "If you called____'s name from behind his back with no visual cues in a noisy room, with people talking and the TV on, what percentage of time would he tum around and respond to you the first time you called"?

0=Never: If the child never does.
1=Rarely: $\begin{aligned} & \text { If the child has done it only once or twice or only } \\ & \text { with multiple repetitions. }\end{aligned}$
3=-Oecasionally: $\begin{aligned} & \text { If he does it about } 50 \% \text { of the time on the first trial or } \\ & \text { does it consistently but, only when the parent repeats } \\ & \text { his name more than once. }\end{aligned}$
4=Always: $\quad \begin{aligned} & \text { If he does it at least } 75 \% \text { of the time on the first try. } \\ & \text { every time just as a normal hearing child would. } \\ & \text { Ask for examples. }\end{aligned}$

PARENT REPORT: 
5. Does the child spontaneously alert to environmental sounds (doorbell, telephone) in the home without being told or prompted to do so?

Ask, "Tell me about the kinds of environmental sounds responds to at home and give me examples". Question parents to be sure the child is responding auditorially only with no visual cues. Examples could be asking about the telephone, doorbell, dog barking, water running, smoke alarm, toilet flushing, engines revving, horns honking, microwave bell, washer changing cycles, thunder, etc. Examples must be child alerting spontaneously and not prompted by parent.

\begin{tabular}{|c|c|}
\hline $0=$ Never: & $\begin{array}{l}\text { If parent can give no examples or if child responds } \\
\text { only after a prompt. }\end{array}$ \\
\hline 1=Rarely: & $\begin{array}{l}\text { If parent can give only one or two examples, or give } \\
\text { several examples where the child's responses are } \\
\text { inconsistent. }\end{array}$ \\
\hline 2=Occasionally: & $\begin{array}{l}\text { If child responds about } 50 \% \text { of the time to more than } \\
\text { two environmental sounds. }\end{array}$ \\
\hline 3=Frequently: & $\begin{array}{l}\text { If child consistently responds to many environmental } \\
\text { sounds at least } 75 \% \text { of the time. }\end{array}$ \\
\hline 4=Always: & $\begin{array}{l}\text { If child basically responds to environmental sounds } \\
\text { the way a hearing child would. If there are a number } \\
\text { of sounds which regularly oecur to which the child } \\
\text { does not alert (even if he consistently responds to two } \\
\text { sounds such as the phone and the doorbell) he would } \\
\text { score no higher than Oecasionally. }\end{array}$ \\
\hline
\end{tabular}

\section{PARENT REPORT:}

6. Does the child alert to auditory signals spontaneously when in new environments?

Ask, "Does your child show curiosity (verbally or nonverbally) about new sounds when in unfamiliar settings, such as in someone else's home or a restaurant by asking, "What was that sound?" or "I hear something?" A younger child may provide nonverbal indications that she has heard a new sound with eye widening, looking quizzical, searching for the source of the new sound, imitation of the new sound (such as when playing with a new toy). Examples parents have reported are children asking about clanging dishes in a restaurant, bells dinging in a department store, PA systems in public buildings, unseen baby crying in another room.

$\begin{array}{ll}\text { 1=Never: } & \text { If parents can give no examples. } \\ \text { 1=Rarely: } & \text { If parents can give only one or two examples. } \\ & \text { If child has done this numerous times and parents cansionally: } \\ \text { give examples. } & \begin{array}{l}\text { If parents can give numerous examples and this is a } \\ \text { common occurrence. }\end{array} \\ & \begin{array}{l}\text { If very few sounds occur without the child asking } \\ \text { about them (or, in the case of the younger child, } \\ \text { showing curiosity nonverbally). }\end{array}\end{array}$

\section{PARENT REPORT:}


7. Does the child spontaneously RECOGNIZE auditory signals that are part of his/her school or home routine?

Ask, "Does regularly recognize or respond appropriately to auditory signals in his/her classroom (e.g., school bell, PA system, fire alarm) or in the home (e.g., running to the window to see which family member is home when s/he hears the garage door opening; going to the table when the bell of the microwave goes off, signaling that the food is cooked and it is time to eat) with no visual cues or other prompts?"

If s/he never does it.
1=Rarely: $\begin{aligned} & \text { If there are one or two instances. } \\ & \text { 2=0ccasionally: If she responds to these signals about } 50 \% \text { of the } \\ & \text { time. }\end{aligned}$

\section{PARENT REPORT:}

8. Does the child show the ability to discriminate spontaneously between two speakers, using audition alone (such as knowing mother's vs. father's voice, or parents' vs. sibling's voice)?

Ask, "Can tell the difference between two voices, like Mom or Dad's (or Susie's or John's) just by listening to them?"

If parent can give no examples of the child
discriminating between two speakers.
1=Rarely: $\quad$ If one or two examples are given.
2=Occasionally: $\begin{aligned} & \text { If several examples are given and the child does this } \\ & \text { at least } 50 \% \text { of the time. }\end{aligned}$
3=Frequently: $\begin{aligned} & \text { If many examples are given and the child does this } \\ & 75 \% \text { of the time. }\end{aligned}$
4=Always:

\section{PARENT REPORT:}


9. Does the child spontaneously know the difference between speech and nonspeech stimuli with listening alone?

Ask, : "Does recognize speech as a category of sounds that are different from nonspeech sounds? For example, if you were standing behind your child and a noise occurred, would she ever say, "What was that noise?" In the case of the younger children, ask, "Would____ever run into the next room to search for a family member's voice versus looking out the window for a dog or fire truck.?"

O=Never:
$\begin{aligned} & \text { If parent can give no examples of the child } \\ & \text { discriminating speech from nonspeech. }\end{aligned}$
1=Rarely:
If one or two examples are given.
$3=$ Frequently: $\quad \begin{aligned} & \text { If many examples are given and the child does this } \\ & \text { at least } 50 \% \text { of the time. }\end{aligned}$
$45 \%$ of the time.
$4=$ Always:

\section{PARENT REPORT:}

10. Does the child spontaneously associate vocal tone (anger, excitement, anxiety) with its meaning based on hearing alone?

Ask, "By listening only, can tell the emotion conveyed in someone's voice such as angry voice, and excited voice, etc.?" (e.g., Father yells at child to "hurry up" through the bathroom door and the child responds, "Why are you mad? and yells back at him. In the case of the younger child, the child starts to cry because of the angry sound in hisher voice). Another example is if the parent is reading a new book to a young child while s/he is sitting on the parent's lap and cannot see their parent's face, (e.g., Mom says "the boy yelled "Let's go!" and the child says "The boy is happy to go to the park").

If $=$ Never:
never had the opportunity to do this.
1=Rarely: $\quad$ If the child does it $25 \%$ of the time.
2=Occasionally: If the child does it about $50 \%$ of the time.
3=Frequently: If she does it $75 \%$ of the time.
4=Always:
$\begin{aligned} & \text { If s/he consistently can identify more than one } \\ & \text { emotion in the listening alone condition. }\end{aligned}$

\section{PARENT REPORT:}

Total points correct: 140

Appendix IV. 


\section{Global Journal of Otolaryngology}

This evaluation gives an overview of the child's use and confidence with the implant. It also gives an overview of the child's hearing capability growth.

Chapter VI: Results

Table 3: Table showing the Little Ears Auditory Questionnaire scores for the children in Group 1 ( $\geq 3$ sessions weekly) along with their age group.

\begin{tabular}{|c|c|c|}
\hline \multicolumn{3}{|c|}{ Group 1 } \\
\hline Child No. & Age (years) & Total score \\
\hline 1 & $>1-2$ & 26 \\
\hline 2 & $>1-2$ & 25 \\
\hline 3 & $>2-3$ & 23 \\
\hline 4 & $>3-4$ & 23 \\
\hline 5 & $>4-5$ & 21 \\
\hline & Average & 23.6 \\
\hline
\end{tabular}

Table 4: Table showing the Little Ears Auditory Questionnaire scores for the children in Group 2 ( 1 session weekly) along with their age group.

\begin{tabular}{|c|c|c|}
\hline \multicolumn{3}{|c|}{ Group 2 } \\
\hline Child No. & Age (years) & Total score \\
\hline 1 & $>1-2$ & 16 \\
\hline 2 & $>2-3$ & 15 \\
\hline 3 & $>2-3$ & 13 \\
\hline 4 & $>3-4$ & 14 \\
\hline 5 & $>3-4$ & 13 \\
\hline 6 & $>4-5$ & 15 \\
\hline 7 & $>4-5$ & 14 \\
\hline 8 & $>5-6$ & 13 \\
\hline 9 & $>5-6$ & 15 \\
\hline 10 & $>5-6$ & 13 \\
\hline & Average & 14.1 \\
\hline
\end{tabular}

Table 5: Table showing MAIS scores for children in Group 1 ( $\geq 3$ Sessions weekly) along with their age group.

\begin{tabular}{|c|c|c|}
\hline \multicolumn{3}{|c|}{ Group 1 } \\
\hline Child No. & Age (years) & Total score \\
\hline 1 & $>1-2$ & 34 \\
\hline 2 & $>1-2$ & 30 \\
\hline 3 & $>2-3$ & 31 \\
\hline 4 & $>3-4$ & 30 \\
\hline 5 & $>4-5$ & 29 \\
\hline & Average & 30.8 \\
\hline
\end{tabular}

The following were the results of the evaluation: Little Ears Auditory Questionnaire: (tables 3 \& 4). The Little Ears Auditory Questionnaire (LEAQ) is a 35 question form that requires an answer as a "Yes" or "No". It is meant to access the auditory development of a child up to the hearing age of 2 years. The average score obtained by Group 1 was 23.6/35 with a standard deviation of 1.95. This was much higher than the average score of 14.1/35 obtained for Group 2, whose scores had a standard deviation of 1.10. As Group 2 includes children of the $>5-6$ age range while Group 1 does not, and as age is discussed as a major factor in the outcomes of the rehabilitation of implantees, an average of the scores of children in Group 2 can be calculated with the omission of the three children in the $>5-6$ age range, in an effort to make the average group scores more comparable (Table 5).

When this is done, the average score for Group 2 is $14.3 / 35$. This result suggests that while including the older children lowered the average score for the group slightly, it did not make a significant enough difference to necessitate the omission of their scores from the study. The scores from Group 1, however, suggest that the younger the child, the better their scores are. This may be due to their sufficient attendance for rehabilitation services. The results for the Meaningful Auditory Integration Scale (MAIS) administered by the parents was as follows (Table 6).

Table 6: Table showing MAIS scores for Group 2 (1 Session weekly) along with their age group.

\begin{tabular}{|c|c|c|}
\hline \multicolumn{3}{|c|}{ Group 2 } \\
\hline Child No. & Age (years) & Total score \\
\hline 1 & $>1-2$ & 25 \\
\hline 2 & $>2-3$ & 26 \\
\hline 3 & $>2-3$ & 28 \\
\hline 4 & $>3-4$ & 27 \\
\hline 5 & $>3-4$ & 25 \\
\hline 6 & $>4-5$ & 30 \\
\hline 7 & $>4-5$ & 27 \\
\hline 8 & $>5-6$ & 25 \\
\hline 9 & $>5-6$ & 25 \\
\hline 10 & $>5-6$ & 24 \\
\hline & Average & 26.2 \\
\hline
\end{tabular}

The MAIS questionnaire can be administered for any age group. It is an interview with the parent to assess the child's wearing habit and confidence with the implant. It also focuses on various auditory development aspects and the behavior of the child in various real life situations. The questionnaire has 10 questions with a maximum possible score of 40 . As seen from the results, Group 1 performed better in this case too, with an average score of 30.8 , which had a standard deviation of 1.92 , compared to Group 2 whose average score was 26.2, with a standard deviation of 1.81. The exclusion of the results of the $>5-6$ age group presented an average score of 26.9. Group 1 scores exhibited an increasing score trend as age decreased for this questionnaire too. The results obtained from both evaluations indicated that Group 1 performed better in both evaluations with higher scores than Group 2.

\section{Chapter VII: Discussion}

\section{Methodological Issues}

There may have been various variables and methodological issues that were not considered during this research and thus 
resulting into a non-conclusive study that requires further refinement. Some of the things that may have influenced the outcomes somehow are:

a) Lack of standardized material for assessment and rehabilitation for Tanzania

b) Lack of knowledge of parents on device use and care. Many children in GROUP 2 had issues with their devices. One may conclude that it was the lack of parent engagement and commitment, but it could also be the lack of knowledge in use and care.

c) The surgery being done abroad, counselling the parents and children was not adequate.

d) Unrealistic expectations of outcomes by the parents may have discouraged them to put efforts into rehabilitation at home. More often than not, parents are not aware of the immense effort required for the sufficient development of speech and language in children.

e) Lack of use of device due to delay in buying spare parts. Since the surgeries were funded by the government and there was no support for spare parts, many parents had to collect the money over time in order to buy the spares and hence during that time the device was not used by the children.

f) The time frame of study was too short to make a comprehensive discussion of the subject of this thesis; as one year of hearing age is not adequate to carry out a comprehensive research study. However, it provides an insight that was not priorly available into the field, and aims to provide direction and a foundation for further developments and studies in the region.

g) The sample size for this research was too small, due to the limited resources and population available for this specific research purpose, but there will be radical changes in Tanzania in this domain in the following years, so further research will be conducted.

h) The birth order of the implantee was not taken into account. This may have influenced the outcomes i.e. Parents with one child may have been more committed to rehabilitation while those with younger siblings may not have been given enough attention.

i) The study was only carried out at one center, due to the lack of adequate centers around the country. With the inauguration of the local cochlear implant programme in Dar es Salaam, Tanzania, awareness of the need for more widely available services is increasing. This study therefore aims to act as a platform for the evaluation of rehabilitation and outcomes for both current and future implantees throughout the country.

\section{Clinical implications}

\section{Future directions}

A longer period of study is required once a National Cochlear Implant Program starts. A lot of variables have to be ironed out especially prior to surgery. Aspects such as the socio-economic status and family dynamics have to be taken into consideration as well. A standardized set of materials needs to be made, or adoption of the one that will be best suitable for the Tanzanian environment is required.

\section{Conclusion}

In conclusion, the results of this study showed that the outcomes obtained from Group 1 seem to be better than the ones from Group 2. Although the research has focused only in one variable of several factors that affect the outcomes of rehabilitation, i.e. number of sessions of attendance to rehabilitation, there are other various factors that influence the outcomes as indicated in the earlier part of this thesis. Parent and family commitment in the process has been highlighted everywhere in this thesis and in the references to various researches. For the best outcomes of rehabilitation of a child with cochlear implant, not only professional help is required from the therapist but also dedication and commitment from the parents and family members. This sometimes involves making sacrifices to make sure the goals set with the therapist with regards to the outcomes are achieved. The child with Cochlear Implant spends at most 3 hours a week only with the therapist for rehabilitation but the rest of the time the child is in the natural growing environment around the family, friends and school, thus they play a major role in the outcomes of the child.

While the results of this study may not be significant enough to make absolute conclusions generalized to a larger population, they emphasize the role of rehabilitation in improving and even ensuring the efficacy of intervention i.e. the cochlear implants. It is imperative that as a national cochlear implant program is being established, rehabilitation should be discussed and resources for rehabilitation should be developed and made available to ensure the best chance at successful outcomes for not only implantees, but all those affected by hearing impairment. It should also be noted that, the earlier the intervention is, the less work will be required for rehabilitation. Later implantation leads to more work and effort to get the desired outcomes. For Tanzania, this has been a challenge as there is no Universal Newborn Hearing Screening program in place and thus identification of children with hearing loss is quite delayed and so is the intervention for the same.

\section{References}

1. Olusanya B, Neumann K, Saunders J (2014) The global burden of disabling hearing impairment: a call to action. Bulletin Of The World Health Organization 92(5): 367-373.

2. Arlinger S (2003) Negative consequences of uncorrected hearing loss a review. International Journal of Audiology 42(2): 2S17-2S20. 
3. Cox R, Alexander G (1995) The Abbreviated Profile of Hearing Aid Benefit. Ear and Hearing 16(2): 176-186.

4. Weinstein B, Ventry I (1982) Hearing Impairment and Social Isolation in the Elderly. Journal of Speech Language and Hearing Research 25(4): 593-599.

5. Blanchfield B, Feldman J, Dunbar J, Gardner E (2001) The severely to profoundly hearing-impaired population in the United States. Journal American Academy of Audiology 12(4): 183-189.

6. WHO Global Estimates on Prevalence of Hearing Loss. (2012) World Health Organization.

7. Stevens G, Flaxman S, Brunskill E, Mascarenhas M, Mathers C, Finucane M (2011) Global and regional hearing impairment prevalence: an analysis of 42 studies in 29 countries. European Journal Of Public Health 23(1): 146-152.

8. Sataloff J (1966) Hearing Loss (1st edn, p. 24). Philadelphia: JB Lippincott Company.

9. Sataloff J, Sataloff R (2006) Occupational Hearing Loss [ $3^{\text {rd }}$ edn] CRC Press 129-161.

10. Teele D, Klein J, Rosner B (1989) Epidemiology of Otitis Media During the First Seven Years of Life in Children in Greater Boston: A Prospective, Cohort Study. Journal of Infectious Diseases 160(1): 8394.

11. Shemesh R (2010) Hearing Impairment: Definitions, Assessment and Management. International Encyclopedia of Rehabilitation.

12. Moore B (2004) Dead Regions in the Cochlea: Conceptual Foundations, Diagnosis, and Clinical Applications. Ear and Hearing, 25(2) 98-116.

13. Purves D, Williams S, Augustine G, Fitzpatrick D (2001) Neuroscience. [ $2^{\text {nd }}$ edn $]$.

14. Von Békésy G, Wever E (1960) Experiments in hearing. New York: Acoustical Society of America through the American Institute of Physics by arrangement with McGraw-Hill Book Co.

15. Chaix B, Lewis R (2016) Speech Audiometry. Cochlea eu.

16. Hearing Loss in Children (2015) National Center on Birth Defects and Developmental Disabilities.

17. Hochheiser S (2013) The History of Hearing Aids.

18. Staab W (2002) Characteristics and use of hearing aids. Audiology.

19. Paul P, Whitelaw G (2011) Hearing and deafness 79: 81-86.

20. Hearing Industries Association: Hearing Aid Sales Up 2.9\% in 2012 (2013).

21. Katz J, Chasin M, English K, Hood L, Tillery K (2015) Handbook of clinical audiology ( $7^{\text {th }}$ edn). Wolters Kluwer Health, Philadelphia, USA, pp. 1-704.

22. McCormack A, Fortnum H (2013) Why do people fitted with hearing aids not wear them? International Journal of Audiology 52(5): 360368.

23. Sockalingam R (2012) Bone Anchored Hearing Systems: Current Developments and Challenges. Audiology Online.

24. Cochlear Implants (2017) National Institute on Deafness and Other Communication Disorders.

25. Hainarosie M, Zainea V, Hainarosie R (2014) The evolution of cochlear implant technology and its clinical relevance. J Med Life 7(Spec Iss 2): $1-4$.

26. Davis-Pedrie D, Shuler-Woodard D (2014) An Overview of Candidacy Consideration for a Cochlear Implant. Colorado School for the Deaf and Blind p. 1-4.
27. Jansen D (2002) Day to Day with My Cochlear Implant.

28. Geers A (2002) Factors Affecting the Development of Speech, Language, and Literacy in Children with Early Cochlear Implantation. Language Speech and Hearing Services In Schools 33(3): 172.

29. Otto B (2010) Language development in early childhood ( $3^{\text {rd }}$ edn.) Upper Saddle River NJ : Merrill.

30. Cooter R, Reutzel D (2004) The essentials of Teaching children to read. Upper Saddle River, New Jersey, USA.

31. Rivers W (1968) Teaching foreign-language skills (1st edn.). Chicago: University of Chicago Press.

32. Lemetyinen H (2012) Language Acquisition Theory. Simply Psychology.

33. Pinker S (1994) The language instinct ( $1^{\text {st }}$ edn.). New York: William Morrow \& Co.

34. Chomsky N, McGilvray J (2009) Cartesian linguistics: A chapter in the history of rationalist thought. Cambridge: Cambridge University Press, USA.

35. Wen H (2013) Chomsky's Language Development Theories: Rescuing Parents out of Dilemma. International Journal of Learning and Development 3(3): 148.

36. Piaget J (1936) The origins of intelligence in children ( $1^{\text {st }}$ edn.).

37. Mc Leod S (2015) Jean Piaget. Simply Psychology.

38. Hickmann M (2001) Language and cognition in development. Pragmatics. Quarterly Publication Of The International Pragmatics Association (Ipra) 11(2): 105-126.

39. Piaget J (1923) Language and Thought in the Child: Studies on the Logic of the Child (1st ed.).

40. Skinner B (1957) The Writer and His Definition of Verbal Behavior. Behav Anal 35(1): 115-126.

41. Vygotsky L (1978) Interaction between learning and development. Readings on The Development Of Children 23(3): 34-41.

42. McLeod S (2014) Lev Vygotsky. Simply Psychology.

43. Vygotsky L (1962) Language and thought ( $1^{\text {st }}$ edn.). Ontario, Canada: Massachusetts Institute of Technology Press.

44. Vygotsky L, Rieber R, Carton A (1987) The collected works of L.S. Vygotsky. Plenum Press, New York, USA.

45. Redmond S (1993) The Critical Period Hypothesis for Language Acquisition and its Implications for the Management of Communication Disorders. National Student Speech Language Hearing Association Journal 20: 25-31.

46. Osberger M, Robbins A, Miyamoto R, Berry S, Myres W, et al. (1991) Speech Perception Abilities of Children with Cochlear Implants, Tactile Aids, or Hearing Aids. American Journal of Otology 12: 105-115.

47. Waltzman S, Cohen N (1998) Cochlear Implantation in children younger than 2 years old. American Journal of Otology 19(2): 158-162.

48. Lenneberg E (1967) The Biological Foundations of Language. Hospital Practice 2(12): 59-67.

49. Yoshinaga-Itano C, Sedey A, Coulter D, Mehl A (1998) Language of Earlyand Later-identified Children with Hearing Loss. Pediatrics 102(5): 1161-1171.

\section{MED-EL Corporation.}

51. Bess F, Dodd-Murphy J (1998) Children with Minimal Sensorineural Hearing Loss: Prevalence, Educational Performance, and Functional Status. Ear \& Hearing, 19(5): 339-354. 
52. Care Pathway for Rehabilitation Team (2017) Central Manchester University Hospitals p. 1-5.

53. Ciorba A, Bianchini C, Pelucchi S, Pastore A (2012) The impact of hearing loss on the quality of life of elderly adults. Clinical Interventions in Aging 7: 159-163.

54. Deafness and hearing loss (2017) World Health Organization.

55. Effects of Hearing Loss on Development. American Speech-Language Hearing Association (2017).

56. Dillon H (2001) Hearing aids. Sydney: Boomerang Press, California, USA.

57. Dobie R, Van Hemel S (2005) Hearing loss. Washington, National Academies Press, Washington, USA.

58. Lin F, Yaffe K, Xia J, Xue Q, Harris T, et al. (2013) Hearing Loss and Cognitive Decline in Older Adults. JAMA Internal Medicine 173(4): 293
59. McCormick B (2014) The Surprising Effects of Untreated Hearing Loss. Starkey.

60. Moeller M (2000) Early Intervention and Language Development in Children Who Are Deaf and Hard of Hearing. PEDIATRICS, 106(3), e43-e43.

61. Plotnick B (2017) Hearing Aids. Healthy Hearing.

62. Quick Statistics About Hearing (2016) National Institute on Deafness and other Communication Disorders.

63. Snow C, Hoefnagel-Hohle M (1978) The Critical Period for Language Acquisition: Evidence from Second Language Learning. Child Development 49(4): 1114-1128.

64. Waltzman S (2005) Cochlear Implantation in Children Younger Than 12 Months. Pediatrics 116(4): e487-e493. 